\title{
PENGARUH PENERAPAN ATURAN ETIKA, PENGALAMAN DAN SKEPTISME PROFESIONAL AUDITOR TERHADAP PENDETEKSIAN KECURANGAN
}

\author{
HELMIATI \\ STIE BANGKINANG \\ helmiati139@gmail.com
}

\begin{abstract}
The purpose of the research study was to aim empirical evidence in analyze the effect of the application of the rules of ethics, experience and professional skepticism auditor's fraud detection and analyze the most dominant variables between the application of the rules of ethics, experience and professional skepticism auditors that influence fraud detection.The population in this study is the KAP (Public Accounting Firm) located in Java and Sumatra by using Convenience Sampling samples were included in the Non-Probability Sampling. The data used is primary data collection method of data using questionnaires. Data analysis method used is multiple regression (Multiple Regression) with SPSS version 21.0.The results of this study indicate that the increase in the application of ethics rules will provide an increase in fraud detection with 2,349 $t$ greater than $t$ table 1.684 and 0.024 significant. Significantly affect fraud detection experience with the $t$ value 2,334, $t$ table 1.684, 0.024 significant. Professional skepticism proved to significantly affect the detection of fraud with 4,230 t, 1,684 t table significantly with 0,000.
\end{abstract}

Keywords : Application of the rules of ethics, experience, and professional scepticism fraud detection

\begin{abstract}
Abstrak: Penelitian ini mempunyai tujuan untuk mengetahui bukti empiris dalam menganalisis pengaruh penerapan aturan etika, pengalaman dan skeptisme profesional auditor terhadap pendeteksian kecurangan serta menganalisis variabel yang paling dominan antara penerapan aturan etika, pengalaman dan skeptisme profesional auditor yang berpengaruh terhadap pendeteksian kecurangan. Populasi dalam penelitian ini adalah KAP (Kantor Akuntan Publik) yang berada di wilayah Jawa dan Sumatera dengan menggunakan sampel Convenience Sampling yang termasuk dalam Non Probability Sampling. Jenis data yang digunakan adalah data primer dengan metode pengumpulan data menggunakan Kuesioner. Metode analisis data yang digunakan adalah regresi berganda (Multiple Regression) dengan bantuan program SPSS Versi 21.0. Hasil penelitian ini menunjukkan bahwa peningkatan penerapan aturan etika akan memberi peningkatan pada pendeteksian kecurangan dengan $t$ hitung 2,349 yang lebih besar dari t tabel 1,684 dan signifikan 0,024. Pengalaman signifikan mempengaruhi pendeteksian kecurangan dengan nilai $\mathrm{t}$ hitung 2,334, $\mathrm{t}$ tabel 1,684, signifikan 0,024. Skeptisme profesional terbukti signifikan mempengaruhi pendeteksian kecurangan dengan $t$ hitung 4,230, $t$ tabel 1,684 signifikan dengan 0,000 .
\end{abstract}

Kata kunci: Penerapan Aturan Etika, Pengalaman, Skeptisme Profesional dan Pendeteksian Kecurangan.

\section{A. Pendahuluan}

Jasa audit yang diberikan Kantor Akuntan Publik berperan dalam mendeteksi kecurangan. Auditor dalam melakukan tugas audit bukan untuk mencari kecurangan, tetapi hanya untuk memperoleh keyakinan bahwa laporan keuangan bebas dari salah saji karena kekeliruan atau kecurangan. Kekeliruan dan kecurangan tergantung dari faktor yang mendasarinya disengaja atau tidak disengaja (Arens, 2006 : 184). Kecurangan adalah faktor yang disengaja yang mengakibatkan adanya salah saji material dalam laporan keuangan dimana laporan keuangan ini adalah subjek utama dalam audit (AICPA AU 316). Oleh karena itu, perlu pemahaman auditor dalam mendeteksi kecurangan. Pendeteksian kecurangan dilakukan auditor berdasarkan kondisi kecurangan dan indikasi (red flag) yang terjadi (Priantara, $2013: 211$ ). 
Kondisi kecurangan terdiri dari tekanan, kesempatan dan rasionalisasi, sementara red flag dapat terlihat dari gaya hidup mewah. Kecurangan akan terjadi bila didukung oleh pengendalian intern yang lemah ( Suroso, 2011, Vol 2, No. 1). Lemahnya pengendalian internal harus bisa dideteksi dengan cepat oleh auditor, dan seorang auditor harus memperoleh pemahaman mengenai pengendalian internal dalam semua penugasan audit (Tuanakotta, 2013 : 352). Skeptisme profesional berdampak signifikan terhadap kualitas audit (Anugerah, 2014). Jika kualitas auditnya bagus, dapat dipastikan pendeteksian kecurangannya bagus. Artinya, skeptisme profesional diperlukan untuk mendeteksi kecurangan. Sikap skeptisme profesional akan membawa auditor pada tindakan untuk memilih prosedur audit yang efektif sehingga diperoleh opini audit yang tepat (Noviyanti, 2008). Aturan etika yang tertuang dalam SPAP haruslah dipatuhi oleh auditor. Beberapa kasus pembekuan izin Akuntan Publik yang melanggar SPAP yaitu Akuntan Publik Justinus Aditya. Menkeu RI terhitung sejak tanggal 28 Nopember 2006 membekukan izin Akuntan Publiknya selama dua tahun. Sanksi tersebut diberikan karena Justinus terbukti melakukan pelanggaran terhadap Standar Profesi Akuntan Publik (SPAP) berkaitan dengan laporan audit atas laporan keuangan konsolidasi PT. Great River International Tbk (Great River) tahun 2003. Selama izinnya dibekukan, Justinus dilarang memberikan jasa atestasi (pernyataan pendapat atau pertimbangan Akuntan Publik) termasuk audit umum, review, audit kerja dan audit khusus.

Pembekuan izin oleh Menkeu ini merupakan tindak lanjut atas Surat Keputusan Badan Peradilan Profesi Akuntan Publik (BPPAP) Nomor 002/VI/SK-BPPAP/VI/2006 tanggal 15 Juni 2006 yang membekukan Justinus dari keanggotaan Ikatan Akuntan Indonesia Kompartemen Akuntan Publik (IAI-KAP). Hal ini sesuai dengan Keputusan Menkeu Nomor 423/KMK 06/2006 tentang Jasa Akuntan Publik sebagaimana telah diubah dengan peraturan Menkeu Nomor 359/KMK 06/2003 yang menyatakan bahwa AP dikenakan sanksi pembekuan keanggotaan dari IAI dan atau IAI-KAP (Hukumonline,2007). Kasus berikutnya adalah kasus Akuntan Publik Djoko Sutarjo yang mengaudit laporan keuangan PT. MYOH Technology Tbk. Kesalahannya cukup fatal karena melanggar SPAP dan kode etik IAI. Menkeu sejak 4 Januari 2007 telah melakukan izin Akuntan Publik (AP) Djoko Sutardjo dari Kantor Akuntan Publik (KAP) Hertanto, Djoko, Ikah \& Sutrisno selama 18 bulan (Hukumonline, 2007).

Berikutnya adalah kasus Akuntan Publik Petrus Mitra Winata. Menteri Keuangan (Menkeu) membekukan izin Akuntan Publik (AP) Drs. Petrus Mitra Winata dari Kantor Akuntan Publik (KAP) Drs. Mitra Winata dan Rekan selama dua tahun, terhitung sejak 15 Maret 2007. Sanksi pembekuan izin diberikan karena melakukan pelanggaran terhadap Standard Profesional Akuntan Publik (SPAP). Pembekuan izin oleh Menkeu sesuai dengan keputusan Menkeu Nomor.423/KMK06/2002 tentang Jasa Akuntan Publik sebagaimana telah diubah dengan peraturan Menkeu Nomor 359/KMK06/2003 (Hukumonline, 2007). Kasuskasus diatas menyebabkan keraguan atas kualitas audit dan integritas auditor Akuntan Publik. Dari fenomena diatas sangatlah jelas bahwa telah terjadi pelanggaran SPAP dan kode etik. Auditor Justinus Aditya, Djoko Sutarjo dan Petrus Mitra Winata harus mendapatkan pembekuan izin dari Menkeu. Fenomena ini membuktikan betapa pentingnya kode etik untuk dipatuhi oleh auditor. Hal inilah yang juga menjadi dasar dari penelitian ini.

SAS 99 adalah dasar dari tinjauan pustaka dalam penelitian ini.Kecurangan (fraud) menurut The Association of Certified Fraud Examiners (ACFE) fraud dalam Priantara ( 2013 : 5) adalah : Perbuatan-perbuatan yang melawan hukum yang dilakukan dengan sengaja untuk tujuan tertentu (manipulasi atau memberikan laporan keliru terhadap pihak lain) dilakukan orang-orang dari dalam atau luar organisasi untuk mendapatkan keuntungan pribadi ataupun kelompok yang secara langsung atau tidak langsung merugikan pihak lain.

Definisi fraud menurut Black Law Dictionary dalam Priantara ( 2013 : 4) adalah: a) Kesengajaan atas salah pernyataan terhadap suatu kebenaran atau keadaan yang disembunyikan dari sebuah fakta material yang dapat mempengaruhi orang lain untuk melakukan perbuatan atau tindakan yang merugikannya, biasanya merupakan kesalahan namun dalam beberapa kasus (khususnya dilakukan secara disengaja) memungkinkan

268 Lembaga Penelitian dan Penerbitan Hasil Penelitian Ensiklopedia $\quad$ E-ISSN: 2657-0300 
merupakan suatu kejahatan; b) Penyajian yang salah/keliru (salah pernyataan) yang secara ceroboh/tanpa perhitungan dan tanpa dapat dipercaya kebenarannya berakibat dapat mempengaruhi atau menyebabkan orang lain bertindak atau berbuat; dan c) Suatu kerugian yang timbul sebagai akibat diketahui keterangan atau penyajian yang salah (salah pernyataan), penyembunyian fakta material, atau penyajian yang ceroboh/tanpa perhitungan yang mempengaruhi orang lain untuk berbuat atau bertindak yang merugikannya.

Ikatan Akuntan Indonesia menyatakan definisi fraud dalam Priantara ( $2013: 4)$ ialah: Setiap tindakan ilegal ditandai dengan penipuan, penyembunyian atau pelanggaran kepercayaan. Tindakan ini tidak tergantung pada aplikasi kekerasan atau ancaman kekerasan fisik. Wikipedia memberikan defenisi fraud dalam Priantara (2013:5) : Kecurangan merupakan penipuan yang dibuat untuk mendapatkan keuntungan pribadi atau untuk merugikan orang lain. Priantara ( 2013 : 68) ACFE membagi fraud ke dalam 3 jenis : Penyimpangan atas asset, pernyataan atau pelaporan yang menipu, korupsi. Ketiga fraud ini dikenal dengan fraud tree. Jenis fraud yang mudah dideteksi adalah penyimpangan atas asset karena dapat diukur dan dihitung dengan teknik auditing dan investigasi. Kondisi-kondisi kecurangan yang disebut dengan segitiga kecurangan dalam Arens ( 2013 : 432):Insentif/Tekanan,Kesempatan,Sikap. Indikasi kecurangan dapat dikenali atau dideteksi dari gejala-gejala atau tanda-tanda (red flag) sebagai berikut dalam Priantara (2013 : 211) Anomali dokumentasi bukti transaksi, Anomali akuntansi, Kelemahan struktur pengendalian intern baik level transaksi maupun level entitas, Anomali dari prosedur analitis, Gaya hidup mewah, Perilaku yang tidak biasa, Pengaduan dan complain.

\section{B. Metodologi Penelitian}

Lokasi pada penelitian ini adalah Kantor Akuntan Publik (KAP) di wilayah Sumatera dan Jawa yaitu : Banda Aceh, Padang, Medan, Batam, Pekanbaru, Bengkulu, Jambi, Lampung, Palembang, Semarang, Jogyakarta, DKI Jakarta, Bandung, Surabaya, . Alasan peneliti melakukan penelitian ini di Kantor Akuntan Publik (KAP) di seluruh wilayah Sumatera dan Jawa adalah karena penelitian dengan populasi seluas ini belum pernah dilakukan. Oleh karna itu, peneliti ingin mengetahui apakah terdapat pengaruh antara aturan etika, pengalaman, dan skeptisme profesional terhadap pendeteksian kecurangan. Waktu penelitian yang dilakukan ini yaitu pada April - September 2016. Populasi pada penelitian ini adalah auditor yang bekerja pada Kantor Akuntan Publik (KAP) di wilayah Sumatera dan Jawa yaitu : Banda Aceh, Padang, Medan, Batam, Pekanbaru, Bengkulu, Jambi, Lampung, Palembang, Semarang, Jogyakarta, DKI Jakarta, Bandung, Surabaya. Tidak diketahui pasti berapa jumlah auditor yang bekerja pada KAP di seluruh wilayah Sumatera dan Jawa. Namun, jumlah KAP yang ada di seluruh Jawa dan Sumatera adalah sebanyak 332 KAP (IAI 2013). Pengambilan sampel dilakukan dengan menggunakan metode Convenience Sampling yaitu pemilihan sampel berdasarkan kemudahan (Aksesibilitas nyaman antara peneliti dengan responden). Jadi, sampel yang diambil adalah 21 KAP (yang memiliki cabang di Sumatera dan Jawa). Berdasarkan hal tersebut ditetapkan jumlah kuesioner yang disebar sebanyak 150 kuesioner. Jenis data dalam penelitian ini adalah data primer yang diperoleh dari jawaban responden atas kuesioner yang diberikan, sedangkan sumber data berasal dari jawaban para auditor yang bekerja di KAP. Data primer adalah data yang diperoleh berdasarkan pengukurannya secara langsung oleh peneliti dari sumbernya (Mustafa,2009:92). Data primer dalam penelitian ini diperoleh melalui kuesioner yang diedarkan dan kemudian dicatat serta diteliti. Pengumpulan data yang dibutuhkan guna mendukung penelitian ini menggunakan metode survey kuesioner. Survey kuesioner merupakan metode survey dengan menggunakan kuesioner penelitian. Pernyataan dalam kuesioner penelitian ini menggunakan Close-Ended Question (Pertanyaan tertutup), dimana jawaban-jawabannya telah dibatasi oleh peneliti sehingga menutup kemungkinan bagi responden untuk menjawab panjang lebar sesuai dengan jalan pikirannya (Kuncoro,2009:177). Skala yang digunakan dalam penelitian ini adalah skala Likert. Skala Likert digunakan untuk mengukur sikap, pendapat, dan persepsi seseorang atau sekelompok orang tentang penomena sosial (Sugiyono,2010:132). Variabel adalah gejala yang bervariasi yang menjadi objek 
penelitian. Variabel dalam penelitian ini adalah aturan etika, pengalaman, skeptisme profesional dan pendeteksian kecurangan. Untuk menentukan skor setiap variabel, penulis perlu memberikan defenisi variabel penelitian. Definisi operasional dari masing-masing variabel tersebut adalah sebagai berikut: Variabel Dependen (Y) Pendeteksian kecurangan adalah mengidentifikasi dan membuktikan kecurangan. (Fullerton dan Durtschi, 2004 : 8). Pengukuran pendeteksian kecurangan dilakukan dengan menggunakan instrument yang dikembangkan oleh Herman (2009) dan Widiyastuti (2009) dengan indikator pengendalian internal, keterbukaan pihak manajemen, lingkungan yang mendukung pelaksanaan audit, identifikasi indikator-indikator kecurangan, karakteristik kecurangan, standard pengauditan untuk pendeteksian kecurangan, faktor-faktor penyebab kecurangan. Variabel independen adalah variabel bebas dan mempengaruhi variabel lain (dependen). Variabel independen dalam penelitian ini adalah penerapan aturan etika, pengalaman, dan skeptisme profesional auditor.

\section{Hasil dan Pembahasan}

Pengujian normalitas menggunakan uji statistik Kolmogorov-Smirnov dan normal probability plot. Dari uji statistik Kolmogorov-Smirnov akan dihasilkan harga taraf signifikansi dengan kriteria pengambilan keputusannya adalah apabila nilai taraf sinifikansi $\geq 0,05$ maka data berdistribusi normal (asumsi terpenuhi). Sebaliknya apabila nilai taraf signifikansi $<0,05$ maka data tidak berdistribusi normal (asumsi tidak terpenuhi).

Tabel Uji Normalitas Data

One-Sample Kolmogorov-Smirnov Test

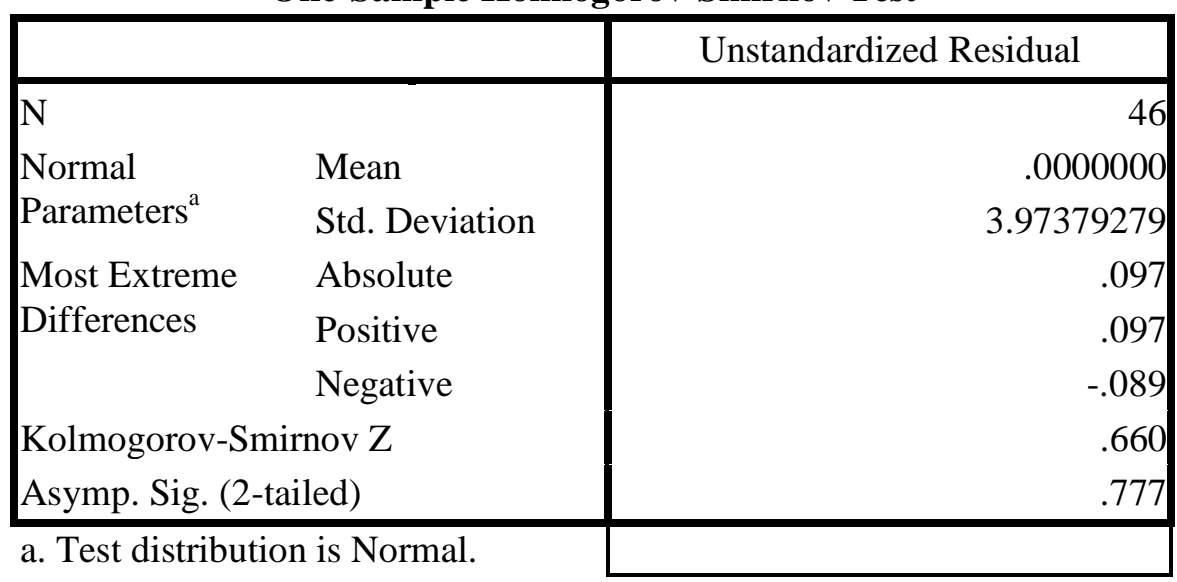

Dari tabel dapat diketahui bahwa residual hasil analisis regresi baik $\mathrm{X}_{1}, \mathrm{X}_{2}, \mathrm{X}_{3}, \mathrm{Y}_{1}$, dan $\mathrm{Y}_{2}$ memiliki probabilitas yang nilainya lebih besar dari 0,05 . Hasil yang sama diperoleh dengan menggunakan metode normal probability plot. Dimana jika data menyebar disekitar garis diagonal maka model regresi memenuhi asumsi normalitas. Sedangkan jika data menyebar jauh dari garis diagonal maka model regresi tidak memenuhi asumsi normalitas.

Pengujian multikolinearitas dapat diketahui melalui nilai tolerance dan nilai Variace Inflation Factor (VIF). Jika tolerance value > 0,10 dan nilai VIF kurang dari 10, maka dapat dikatakan tidak terjadi multikolinearitas.

\begin{tabular}{|l|c|c|}
\hline \multicolumn{1}{|c|}{ Variabel Bebas } & Tolerance & VIF \\
\hline Penerapan aturan etika & .511 & 1.958 \\
\hline Pengalaman auditor & .414 & 2.417 \\
\hline Skeptisme Profesional auditor & .682 & 1.466 \\
\hline
\end{tabular}

Uji Heteroskedastisitas dalam penelitian ini menggunakan Spearman's Rank Correlation Test. Kriteria pengambilan keputusannya adalah jika taraf signifikansi $\geq 0,05$ maka tidak terjadi heteroskedastisitas. Sebaliknya jika taraf signifikansi $<0,05$ maka terjadi heteroskedastisitas. Hasil uji Spearman's Rank Correlation Test menunjukkan bahwa nilai taraf signifikansi masing-masing variabel bebas memiliki taraf signifikansi $\geq 0,05$. 


\section{Correlations}

\begin{tabular}{ll|r|r|r|}
\hline & $\begin{array}{c}\text { Aturan } \\
\text { Etika }\end{array}$ & Pengalaman & $\begin{array}{c}\text { Skeptisme } \\
\text { Profesional }\end{array}$ \\
\hline Aturan Etika & Correlation Coefficient & 1.000 & .249 & .126 \\
& Sig. (2-tailed) &. & .095 & .403 \\
& $\mathrm{~N}$ & 46 & 46 & 46 \\
\hline Pengalaman & Correlation Coefficient & .249 & 1.000 & .163 \\
& Sig. (2-tailed) & .095 &. & .278 \\
& $\mathrm{~N}$ & 46 & 46 & 46 \\
\hline Skeptisme & Correlation Coefficient & .126 & .163 & 1.000 \\
Profesional & Sig. (2-tailed) & .403 & .278 & \\
& $\mathrm{~N}$ & 46 & 46 & 46 \\
\hline
\end{tabular}

Pengujian hipotesis dalam penelitian ini menggunakan uji t untuk mengetahui pengaruh variabel independen terhadap variabel dependennya secara parsial. Proses perhitungan menggunakan SPSS melalui analisis regresi linier dan hasilnya dapat dilihat pada tabel Coefficiennts. Dari hasil uji t, maka akan diketahui level of significant dari setiap variabel bebas terhadap variabel terikatnya. Apabila nilai signifikan lebih kecil dari Alpha $5 \%$ maka secara parsial variabel bebas berpengaruh terhadap variabel terikatnya, dan begitu pula sebaliknya.

Hasil analisis regresi linear berganda diperoleh persamaan regresi sebagai berikut: $\mathrm{Y}=1,625+0,413 \mathrm{X}_{1}+0,348 \mathrm{X}_{2}+0,531 \mathrm{X}_{3}+\mathrm{e}$

Arti dari persamaan regresi linier berganda diatas adalah: a) Nilai konstanta (a) sebesar 1,625. Artinya adalah apabila variabel independen diasumsikan nol (0), maka pendeteksian kecurangan bernilai 1,625 ; b) Nilai aturan etika sebesar 0,413 . Artinya adalah bahwa setiap aturan etika sebesar 1 satuan maka akan meningkatkan pendeteksian kecurangan sebesar 0,413 dengan asumsi variabel lain tetap; c) Nilai koefisien regresi pengalaman sebesar 0,348. Artinya adalah bahwa setiap peningkatan pengalaman sebesar 1 satuan maka akan meningkatkan pendeteksian kecurangan sebesar 0,348 dengan asumsi variabel lain tetap; d) Nilai koefisien skeptisme profesional sebesar 0,531. Artinya adalah bahwa setiap peningkatan skeptisme profesional auditor sebesar 1 satuan maka akan meningkatkan pendeteksian kecurangan sebesar 0,531 dengan asumsi variabel lain tetap; e) Standar error (e) merupakan variabel acak dan mempunyai distribusi probabilitas yang mewakili semua faktor yang mempunyai pengaruh terhadap Y tetapi tidak dimasukan dalam persamaan.

Koefisien determinasi $\left(\mathrm{R}^{2}\right)$ pada intinya mengukur seberapa besar sumbangan pengaruh variabel bebas (penerapan aturan etika, pengalaman, skeptisme profesional auditor) dalam menerangkan variasi variabel terikat (pendeteksian kecurangan).

\section{Tabel Uji t}

\begin{tabular}{|l|c|r|r|r|}
\hline Model & R & R Square & Adjusted R Square & \multicolumn{1}{|c|}{ Std. Error of the Estimate } \\
\hline 1 & $.841^{\mathrm{a}}$ & .707 & .686 & 4.11327 \\
\hline
\end{tabular}

Hal ini menunjukan bahwa pendeteksian kecurangan dipengaruhi oleh variable independen (penerapan aturan etika, pengalaman auditor dan skeptisme profesional) sebesar $70,7 \%$, sedangkan sisanya 29,3\% variabel independen (penerapan aturan etika, pengalaman dan skeptisme profesional.

Variabel penerapan aturan etika terhadap pendeteksian kecurangan terbukti signifikan mempengaruhi pendeteksian kecurangan. Hasil uji variabel ini menunjukan probabilitas 0,024 lebih kecil dari batas signifikansi yang digunakan $(0,05)$ serta uji t menghasilkan nilai $t_{\text {hitung }}$ $2,349>t_{\text {tabel }} 1,684$. Nilai $t_{\text {hitung }}$ yang lebih besar dari $t_{\text {tabel }}$ menyatakan hipotesis penelitian dapat diterima. Koefisien variable ini $(0,413)$ secara jelas memberikan gambaran hubungan yang searah atau dengan kata lain peningkatan penerapan aturan etika akan memberi peningkatan

\begin{tabular}{lll}
\hline E-ISSN: 2657-0300 & Lembaga Penelitian dan Penerbitan Hasil Penelitian Ensiklopedia & 271 \\
P-ISSN: 2657-0319 &
\end{tabular}


pada pendeteksian kecurangan. Aturan etika itu adalah Independensi, integritas, objektifitas, kerahasiaaan dan kehati-hatian. Independensi dapat dilihat dengan cara pandang yang tidak bisa dalam pelaksanaan pengujian audit, bebas dari pengaruh, tidak dikendalikan oleh pihak lain dan tidak tergantung pada orang lain.

Pengaruh pengalaman auditor berpengaruh terhadap pendeteksian kecurangan. Hasil penelitian menunjukkan nilai signifikansi atau $p$ value varaibel pengalaman auditor sebesar $0,024<0,05$ sehingga pengalaman auditor berpengaruh signifikan terhadap pendeteksian kecurangan, sehingga $\mathrm{H} 2$ terbukti kebenarannya. Hasil uji variabel ini menunjukan probabilitas 0,024 lebih kecil dari batas signifikansi yang digunakan $(0,05)$ serta uji $t$ menghasilkan nilai $t_{\text {hitung }} 2,334>t_{\text {tabel }} 1,684$. Nilai $t_{\text {hitung }}$ yang lebih besar dari $t_{\text {tabel }}$ menyatakan hipotesis penelitian dapat diterima. Koefisien variable ini $(0,348)$ secara jelas memberikan gambaran hubungan yang searah atau dengan kata lain peningkatan pengalaman auditor akan memberi peningkatan pada pendeteksian kecurangan.

Pengaruh skeptisme profesional auditor terhadap pendeteksian kecurangan. Hasil penelitian menunjukkan nilai signifikansi atau $p$ value variabel skeptisme profesional auditor sebesar $0,000<0,05$ sehingga skeptisme profesional auditor berpengaruh signifikan terhadap pendeteksian kecurangan, sehingga $\mathrm{H} 3$ terbukti kebenarannya. Hasil uji variabel ini menunjukan probabilitas 0,000 lebih kecil dari batas signifikansi yang digunakan $(0,05)$ serta uji $\mathrm{t}$ menghasilkan nilai $\mathrm{t}_{\text {hitung }} 4,230>\mathrm{t}_{\text {tabel }} 1$,684. Nilai $\mathrm{t}_{\text {hitung }}$ yang lebih besar dari $\mathrm{t}_{\text {tabel }}$ menyatakan hipotesis penelitian dapat diterima.

\section{Penutup}

Penerapan aturan etika berpengaruh signifikan terhadap pendeteksian kecurangan auditor. Pengalaman auditor berpengaruh signifikan terhadap pendeteksian kecurangan auditor. Skeptisme profesionalisme auditor berpengaruh signifikan terhadap pendeteksian kecurangan auditor.

\section{Daftar Pustaka}

Alim, Nizarul dkk. 2007. "Pengaruh Kompetensi dan Independensi Terhadap Kualitas Audit Dengan Etika Auditor Sebagai Variabel Moderasi". Simposium Nasional Akuntansi X;AVEP 08, Hal.1-26.

De Angelo, L.E. 1981. "Auditor Size and Audit Quality". Journal of Accounting \& Economic 3 (December): 183-199.

Elfarini, Eunike Christiani. 2007. "Pengaruh Kompetensi dan Independensi Auditor Terhadap Kualitas Audit". Semarang. Universitas Negeri Semarang.

Fullerton, Rosemary, and Cindy Durtschi. 2005. "The Effect of Professional Skepticism on The Fraud Detection Skills of Internal Auditors" Working Paper.

Ghazali, Imam. 2005. "Aplikasi Analisis Multivariate dengan Program SPSS". Semarang. Badan Penerbit Universitas Diponegoro.

HukumOnline. 2007. "Menkeu Bekukan Izin Tiga Akuntan Publik". Hukumonline.com Diakses tanggal.22 November 2016.

Institut Akuntan Indonesia. 2008. "Kode Etik Akuntan Publik". Jakarta salemba Empat.

International Auditing and Assurance Standards Boards (IAASB). 2004 "International Standard on Auditing". New York : IFAC.

Kopp, Lori, Lemon, W. Morley, Rennie, Morina, 2003. "A Model of Trust and Profesional Skepticism in the Auditor-Client Relationship". Presentation, School of Accountancy Seminar Series.

Kuncoro, M. 2009. "Metode Riset untuk Bisnis dan Ekonomi Bagaimana Meneliti dan Menulis Tesis". Jakarta. Erlangga.

Hall A. James dan Singleton Tommie, 2007."Audit dan Assurance Teknologi Informasi". Jakarta. Penerbit Salemba Empat. 
Hamid, Abdul. 2007."Pedoman Penulisan Skripsi", Jakarta. Fakultas Ekonomi dan Ilmu Sosial Universitas Islam Negeri Syarif Hidayatullah.

Herliansyah, Yudhi dan Ilyas, Meifida. 2006. "Pengaruh Pengalaman Auditor terhadap Bukti tidak Relevan dalam Auditor Judgment”. Padang. Simposium Nasional Akuntansi 9.

Herman, Edi. 2009. "Pengaruh Pengalaman dan Skeptisme Profesional Auditor terhadap Pendeteksian Kecurangan". Fakultas Ekonomi dan Ilmu Sosial UIN Syarif Hidayatullah Jakarta.

Hogan, E, Chris. Dkk. 2008. "Financial Statement Fraud: Insights From the Academic Literature". A Journal of Practice \& Theory Vol. 27, No. 2 (Page. 231-252)

Ikatan Akuntansi Indonesia. 2001. "Standar Profesi Akuntan Publik". Jakarta. Salemba.

Indriantoro, Nur, Supomo, Bambang. 2002. "Metodologi Penelitian Bisnis untuk Akuntansi dan Manajemen". Yogyakarta, Edisi Pertama; cetakan kedua. BPFE UGM.

Institut Akuntan Publik Indonesia. 2008. "Kode Etik Akuntan Publik”. Jakarta Salemba.

Jaya Putra Syofiansyah \& Durachman Yusuf. 2009. "Etika Bisnis \& Hak Kekayaan Intelektual". Jakarta. Lembaga Penelitian UIN Syarif Hidayatullah.

Kusumastuti, Rika Dewi. 2008. "Pengaruh Pengalaman, Komitmen Profesional, Etika Organisasi dan Gender Terhadap Pengambilan Keputusan Etis Auditor. FEIS UIN syarif Hidayatullah. Jakarta.

Ludigdo, Unti. 2006. "Strukturisasi Praktik Etika di Kantor Akntan Publik: Sebuah Studi Interpretif". Simposium Nasional Akuntansi 9 Padang.

Louwer, Timothy J. Ramsay, Robert J. Sinason, David H. and Strawser, Jerry R. 2005. Auditing and Assurance Service. New York : Mc Graw Hill

Nachrowi. D, Nachrowi dan Usman, Hardius. 2006. "Ekonometrika Untuk Analisis Ekonomi dan Keuangan".Jakarta. Fakultas Ekonomi Universitas Indonesia.

Narbuko, chalid dan Achmad, Abu. 2008." Metode Penelitian", Jakarta. Bumi Aksara.

Noviyanti, Putri dan Bandi. 2002. "Pengaruh Pengalaman dan Pelatihan Terhadap Struktur Pengetahuan Auditor Tentang Kekeliruan ". Simposium Nasional Akuntansi 5.

Noviyanti, Suzy. 2008. "Skeptisme Profesional Auditor dalam Mendeteksi Kecurangan". Jurnal Akuntansi dan Keuangan Indonesia. Vol. 5, No. 1 (Hal. 102-125).

Nugroho, Bhuono Agung. 2005."Strategi Jitu Memilih Metode Statistik Penelitian dengan SPSS". Yogyakarta.

Payne, Elizabeth A, and Ramsay, Robert J. "Fraud Risk Assessment and Auditors Professional Skepticism“. Managerial Auditing Journal 20 no. 3 (2005) : 321 - 330

Petty, R. E. Wegener, D. T, Fabrigar, L. R. "Attitudes and Attitude Change”. Annual Reviesw of Psychology 48 ( 1997) : $609-647$

Priantara, Diaz. 2013. "Fraud Auditing \& Investigation". Jakarta.

Rahayu, Siti Kurnia dan Ely Suhayati. 2010 "Auditing, Konsep Dasar Pedoman Pemeriksaan Akuntan Publik". Yogyakarta, Graha Ilmu.

Ramaraya, Tri. 2008. "Pendeteksian Kecurangan (Fraud) Laporan Keuangan Oleh Auditor Eksternal". Jurnal Akuntansi dan Keuangan, vol. 10, No. 1 (Hal. 23-33).

Setiawan, Wawan. 2003. "Fraud : Suatu Tinjauan Teoritis “. Kompak No. 7, Hal 137 - 154

Siegel, G. and Marconi, H. R. Behavioral Accounting. Cincinnati, Ohio : South - Western Publishing Co, 1989

Sugiyono, 2007. " Metode Penelitian Kunatitatif, Kualitatif dan R\&D”. Bandung. CV. ALFABETA.

Shaub, Michael K, and Janice E. Lawrence. "Ethics, Experience and Professional Skepticism : A Situational Analysis". Behavioral research in Accounting 8, Supplement (1996) : 124 $-157$

Shaub, Michael K, and Janice E. Lawrence. " Response to Comments on Ethics, Experience and Professional Skepticism : A Situational Analysis". Behavioral Research in Accounting 8, Supplement (1996) : 170 - 172 
Taufik, Muchamad. 2008. "Pengaruh Pengalaman Kerja dan Pendidikan Profesional Auditor Internal Terhadap Kemampuan Mendeteksi Frad". Fakultas ekonomi dan Ilmu Sosial UIN Syarif Hidayatullah Jakarta.

Tirta, Rio dan Sholihin, Mahfud. 2004. "The Effects of Experience and Task Spesific Knowledge on Auditor's Performance in Assesing A Fraud Case “. Jurnal Akuntansi dan Auditing Indonesia. Vol 8, No. 1

Utami Wiwik dan Fitri Indriawati. 2006. "Muatan Etika Dalam Pengajaran Akuntansi Keuangan dan Dampaknya Terhadap Persepsi Etika Mahasiswa: Studi Eksperimen Semu”. Simposium Nasional Akuntansi 9 Padang.

Widiyastuti, Rani. 2009. “ Analisis Pengaruh Pengalaman, Kompetensi \& Integritas Auditor Eksternal Terhadap Kemampun Auditor Dalam Mendeteksi Kecurangan”. Fakultas Ekonomi dan Ilmu Sosial UIN Syarif Hidayatullah Jakarta.

Winartono, Ratih. 2004. "Etika”. Majalah Auditor, PT. Auditor Media Citra Pariwara. 